\title{
The Role of Work Engagement in Moderating the Impact of Job Characteristics, Perceived Organizational Support, and Self-Efficacy on Job Satisfaction
}

\author{
Adhe Rachman Sulistyo ${ }^{1}$, Suhartini ${ }^{2}$ \\ ${ }^{1,2}$ Islamic University of Indonesia \\ suhartini@uii.ac.id
}

\begin{abstract}
This research is aimed at figuring out the extent to which job characteristics, perceived organizational support and self-efficacy affect job satisfaction with work engagement serving as an intervening variable. The respondents of this research were 101 employees of the Centre for the Development and Empowerment of Educators and Educational Personnel (P4TK) of Art and Culture of Yogyakarta. The data were collected using questionnaires. The data were analyzed quantitatively and qualitatively. The quantitative analysis techniques used in this research were t-test, F-test, multiple regression analysis and path analysis. The research yielded some results. Firstly, job characteristics and self-efficacy had a significant effect on work engagement and perceived organizational support did not have any significant effect on work engagement, but together it had a significant effect on work engagement. Secondly, job characteristics and perceived organizational support had a significant effect on job satisfaction, and self-efficacy did not have any significant effect on job satisfaction, but together it had a significant effect on job satisfaction. Thirdly, work engagement had a significant effect on job satisfaction. Fourthly, job characteristics and perceived organizational support had a greater effect on job satisfaction directly, and self-efficacy had a greater effect on job satisfaction indirectly through work engagement. The results of this research can be used as a reference for P4TK to improve employees' job satisfaction, and ultimately, support the achievement of organizational goals.
\end{abstract}

Article Info

- Received : October 29, 2018

- Revised : December 13, 2018

- Published : January 05, 2019

- No. Pages : $15-31$

- DOI : 10.33019/ijbe.v3i1.112

- JEL : J28, L3

- Keywords : work engagement, job characteristics, perceived organizational support, selfefficacy, job satisfaction

\section{Introduction}

When an organization manages human resources, the issue of job satisfaction often arises. According to Colquitt et al. (2013), employees' job satisfaction is an emotion aroused from one's judgment on a job or an experience of his or her job. In other words, it is how an individual perceives his or her job and what he or she thinks about his or her job. Job satisfaction holds 
importance as it has both positive consequences (if the employee is satisfied with his or her job) and negative consequences (if the employee is dissatisfied of his or her job).

Kreitner \& Kinicki (2013) stated that when an employee is dissatisfied of his or her job, there is a high chance that he or she will show a negative attitude towards his or her job, for example, increased absenteeism, turnover, feeling stressed out, and lowered performance. On the other hand, an employee's job satisfaction brings about positive consequences in the form of positive attitude that goes hand in hand with job satisfaction, for example, increased motivation, work engagement, organizational commitment, organizational citizenship behaviour, and performance. Saks (2006) explained that the employee's work engagement influences job satisfaction. If work engagement is established, one of the consequences possibly occurs an employee's satisfaction with his or her job. Employee's engagement is an important concept to be developed by an organization within the last 20 years. According to Bedakar \& Pandita (2014), an organization uses this concept as its strategic partners in its business, with work engagement will leave the sense of wealth in the job.

Robbinson \& Judge (2017) defined work engagement as an extent to which an individual feels engaged, satisfied, and enthusiastic about his or her job. Work engagement is an umbrella covering various consequences in work as well as other variables that may support the organization to achieve its goals. In general, it is arguable that the idea of creating a positive attitude in an employee in working and maximizing what he or she has at the same time will open employee engagement.

Kahn (1990) explained that one would be engaged in his or her work when the job gives him or her psychological meaningfulness, psychological safety, and psychological availability. The psychological meaningfulness dimension means that one feels the sense of return of investment in work or performance. This dimension is closely related to work design. Some things points can arouse the sense of meaningfulness in work, one of which is a task. Tasks or works that may evoke a sense of meaningfulness are those that pose a challenge to the employee, require varied abilities, encourage creativity, allow autonomy, and is accompanied with clear procedures. The perceived organizational support may create the psychological safety dimension. The psychological safety dimension refers to an employee's sense of ability to show his or her self in work and lack of fear of negative consequences that can arise from his or her performance. An organization's members feel at ease in their work environment when the organization allows openness and gives supportive encouragement to them, which is only possible when the organization gives social encouragement. Eisenberger et al. (2001) added that perceived organizational support refers to one's general belief that his or her organization appreciates his or her contribution and cares about his or her well-being. It is arguable that the employee believes that the organization is concerned and cares about his or her welfare, and for this reason, he or she will pay back with engagement with his or her work or organization.

Kahn (1990) argued that the psychological availability dimension could forge self-efficacy in an employee. The psychological availability dimension is the sense of ownership of physical, emotional, and psychological sources one requires for self-investment in performing a job. Meanwhile, Robbinson \& Judge (2017) stated that this dimension could be achieved when an employee has confidence in his or her status or ability to handle a job. Self-efficacy refers to an 
individual's confidence in his or her abilities and capabilities to perform a task. It is arguable that self-efficacy can fill the psychological availability condition, which later leads to employee engagement to his or her work.

P4TK in the arts and culture field is an organization under the government with the main function of fostering, developing, and improving the competence of teachers of vocational high school-art and craft group across Indonesia. It is arguable that the roles and tasks of P4TK are quite vital for the development in the arts and culture field in Indonesia. Hence, P4TK must be able to manage employees' job satisfaction so the members can work properly. Based on the results of performance evaluation in the List of Civil Servant Work Conduct (DP3) of P4TK, there were decreases in the performance of P4TK employees from 2015 to 2016 in some indicators of P4TK employees work behaviour, including P4TK employee commitment that decreased by $15.5 \%$ or 47 out of 303 employees had decreased commitment; service orientation that decreased by $2.6 \%$ or 8 employees had decreased service orientation; decreased integrity that decreased by $6.6 \%$ or 20 employees had decreased integrity; employee discipline that decreased by $6.6 \%$ or 20 employees had decreased discipline; and employee cooperation that decreased by $5.6 \%$ or 17 employees had decreased cooperation.

The levels of work engagement and job satisfaction of P4TK employees are presumed to have yet to be well-established. They are not satisfied with their job, and thus, show negative attitudes such as decreased commitment, service orientation, integrity, discipline, and cooperation between employees. Concerning the problem and relationship above mentioned, it can be said that employees' job satisfaction is assumed to have resulted from their engagement with their work, while the employees' engagement with their work is assumed to result from the job characteristics, perceived organizational support, and self-efficacy. Given the importance of job satisfaction of employees in P4TK and how important it is to engage employees with their job, as well as the relationship explained above, this research was conducted.

\section{Literature Reviews}

Job characteristics. According to Hackman \& Oldham in Bohlander \& Snell (2013), job characteristics model is a work design theory comprising three psychological conditions (work experience meaningfulness, accountability for work outcome, and knowledge of work outcome) perceived by an individual for improving performance and internal motivation and lowering absenteeism and turnover. The core components of job characteristics are skill variation, task identity, task significance, autonomy, and feedback. Perceived Organizational. Support. Rhoades \& Eisenberger (2002) explained that perceived organizational support is an employee's general belief about the extent to which an organization appreciates his or her contribution and care about his or her welfare. The organizational support perceived by the employee has meant that what he or she has invested in the organization will be rewarded and appreciated by the organization, showed by the organization's care about his or her well-being, consistency between goal and value of the organization and the employee, organization's concern about the employee, organization's concern about the employee's opinion, an organization's willingness to assist the employee, give forgiveness, and give opportunity.

Self-Efficacy. Kreitner \& Kinicki (2013) defined self-efficacy as one's belief in his or her chance of completing a given task successfully. The calculation of self-efficacy involves 
cognitive assessment of the interaction between his or her ability and situational opportunity as well as an existing obstacle. In short, Bandura (1997) argued that self-efficacy perceived is not focused on the level of ability one has, but on his or her belief in conducting activities in various circumstances. Self-efficacy measurement scale consists of three main components, namely level, generality, and strength.

Work Engagement. According to Schaufeli, et al. (2002), work engagement refers to the behaviour of an employee who devotes him- or herself completely to his or her job. In other words, engagement is defined as the sense of the usefulness of a member of an organization in his or her work. When feeling engaged, an employee will devote and express his or her physique, cognition, emotion, and mentality. Work engagement is contrary to burnout attitude. That being said, work engagement is a positive attitude of an employee toward his or her work, which consists of vigour, dedication, and absorption.

Job Satisfaction. Job satisfaction reflects the extent to which an individual favours his or her job. Kreitner \& Kinicki (2013) defined job satisfaction as an effective or emotional response to different aspects of a job. This definition implies that job satisfaction is a relative concept rather than an uniter concept. An individual may be satisfied with an aspect of a job and dissatisfied with another aspect. According to Smith, Kendall, \& Hulins in Collquit et al. (2013), there are some aspects of the job that may create job satisfaction, namely satisfaction with salary, satisfaction with promotion, satisfaction with direct supervisor, satisfaction with colleagues, and satisfaction with work.

\section{Influence of Job Characteristics, Perceived Organizational Support, and Self-Efficacy on Work Engagement}

According to Kahn (1990), one will feel engaged to his or her work when he or she is under a psychological condition in which he feels the sense of meaningfulness, safety, and availability when working. One will feel the sense of meaningfulness when the task given to him or her is full of challenges, is varied, encourages creativity, allows autonomy, and the objectives and procedures of which are well-explained. Additionally, meaningfulness can be achieved when there are role characteristics and interactions during work. Meanwhile, the psychological condition safety can be achieved when there are a social system, interpersonal relationship, group dynamics, managerial style, and organizational norm. As for psychological condition availability, it can be achieved when there is a gap to which one can contribute, emotional energy that can be poured into the work, level of confidence in one's status and abilities, and a work that may affect others. According to Saks (2006), perceived organizational support and job characteristics have a significant effect on or can predict the presence of work engagement. He also stated that both variables significantly affect work engagement and organizational engagement. The results of the research by Akingbola \& Van Den Berg (2010) showed that when an employee is engaged in every work activity, receives works requiring unique competencies, and receives an opportunity to participate in decision making, he or she will feel a significant sense of engagement with the work and non-profit organization as he or she perceives the work to be meaningful for public interest, and there is a consistency between his or her value and that of the organization. The results of research by Kittredge (2010) also showed that job characteristics have a significant relationship with work engagement. Krishnan et al. (2015) explained that when an organization gives a work that can provide motivation and leave a social impact, the employee will feel attached to his or her work. 
The results of the research by Rich (2010) showed that perceived organizational support has a positive, significant effect on work engagement, in which case, an employee will feel engaged to his or her work if he or she perceives organizational support as high. The research by Burns (2016) also showed similar results, where perceived organizational support serves as an independent variable as well as a predictor of work engagement. In their research, Jin \& McDonald (2016) proved specifically that there is a positive relationship between perceived organizational support and work engagement. Unlike the above research, the research by Nusantria (2012) showed that perceived organizational support has a positive, albeit insignificant, effect on work engagement. He found that the variable perceived organizational support has a positive effect on the work engagement of the employees of PT Telekomunikasi Indonesia Semarang. The results of the research by Yakin \& Erdil (2012) showed that selfefficacy has a significant effect on work engagement, and confidence has a significant, positive effect on the entire dimension of work engagement. The research by Scaufeli \& Salanova (2007) also found that self-efficacy has a positive, significant effect on work engagement and that selfefficacy is a perfect predictor of work engagement. According to Sukmawati et al. (2015), personal resources that include self-efficacy has a direct effect on work engagement. Kahn (1990) argued that one would be engaged to his or her work under psychological conditions of meaningfulness, safety, and availability.

According to the abovementioned relationships, the following hypotheses are proposed:

H1a: Job characteristics influence work engagement.

H1b: Perceived organizational support influence work engagement.

H1c: Self-efficacy influence work engagement.

H1d: Job characteristics, perceived organizational support, and self-efficacy influence work engagement.

\section{Influence of Job Characteristics, Perceived Organizational Support, and Self-Efficacy on Job Satisfaction}

The results of the research by Hauff et al. (2015) showed that job satisfaction is influenced by many factors, including interesting work and good relationship between an employee and his or her manager as well as colleagues. Hung \& Huang (2014) also proved that job characteristics that consist of variety, autonomy, identity, feedback, cooperation, and friendship have a positive, significant effect on job satisfaction. Similarly, Milette \& Gagne (2008) also showed that job characteristics have a positive, significant effect on employees' positive attitude toward their work, including job satisfaction.

Hasan et al. (2014) and Biswas \& Bhatnagar (2013) concluded that perceived organizational support has a positive, significant effect on job satisfaction, while Shacklock et al. (2013) proved that there is a significant relationship between perceived organizational support and job satisfaction. Borgogni et al. (2013) stated that self-efficacy has a positive, significant effect on job satisfaction. An individual who is confident in his or her competence and believes that he or she can control his or her work will feel a sense of satisfaction with his or her work. Lai \& Chen (2012) also stated that self-efficacy has a positive relationship with job satisfaction. An individual with high self-efficacy will have superior experience and ability, which will increase his or her satisfaction and performance. Contrary to the results of the above research, Kuru \& Katsaras (2016) stated that there is no significant correlation between job satisfaction and self- 
efficacy. Duggleby et al. (2009) also stated that self-efficacy does not have any significant effect on job satisfaction.

Based on the abovementioned relationships, the following hypotheses are proposed:

H2a: Job characteristics influence job satisfaction.

$\mathrm{H} 2 \mathrm{~b}$ : Perceived organizational support influence job satisfaction.

H2c: Self-efficacy influence job satisfaction.

H2d: Job characteristics, perceived organizational support, and self-efficacy influence job satisfaction.

\section{Influence of Work Engagement on Job Satisfaction}

Saks (2006) proved that when work engagement and organizational engagement arise, job satisfaction can result. Both work engagement and organizational engagement influence or predict job satisfaction. The results by Ramos \& Almeida (2017) showed that work engagement has a positive, significant effect on job satisfaction. The regression analysis results of the research by Mache et al. (2014) proved that work engagement has a positive, significant effect on job satisfaction and life quality of surgery specialist clinic employees in Germany.

According to the abovementioned relationships, the following hypothesis is proposed:

H3: Work engagement influences job satisfaction.

Direct or Indirect Influence among Job Characteristics, Perceived Organizational Support, and Self-Efficacy on Job Satisfaction or Through Work Engagement

Saks (2006) proved that employees' work engagement might mediate the relationship between job characteristics as well as perceived organizational support and job satisfaction. This research also proved that the effect of job characteristics and perceived organizational support on job satisfaction decreased from $42 \%$ to $15 \%$ after variable work engagement was added. In other words, the direct effect of variables job characteristics and perceived organizational support on job satisfaction was higher than their direct effect through work engagement. Yakin \& Erdil (2012) found that self-efficacy affects not only work engagement but also job satisfaction. This research proved that work engagement mediates the relationship between self-efficacy and job satisfaction.

Based on the abovementioned relationships, the following hypothesis is proposed:

H4: The direct influence (job characteristic, perceived organizational support and self-efficacy on job satisfaction) is greater than the indirect influence (job characteristic, perceived organizational support and self-efficacy on job satisfaction through work engagement).

\section{Research Methods}

\section{Research Type}

The research conducted was quantitative research.

\section{Research Location}

This research was conducted at P4TK in the Arts and Culture field previously known as the Center for Development and Improvement of Teachers (PPPG) of Arts of Yogyakarta located on Jl. Kaliurang KM. 12.5, Klidon, Sukoharjo, Ngaglik, Sleman, Yogyakarta. 


\section{Research Variable Identification}

Independent variables $(\mathrm{X})$ : job characteristics (X1), perceived organizational support (X2), and self-efficacy (X3). Dependent variable (Y): job satisfaction. Intervening variable (Z): work engagement.

\section{Operational Definition of Variables and Indicators}

Job characteristics (X1). In this research, job characteristics are defined as a core dimension of a work assigned to an employee, with indicators skill variation, task identity, task significance, autonomy, and feedback (an extent to which information about work outcome is provided directly and clearly). Perceived Organizational Support (X2). In this research, perceived organizational support is defined as the perception on the extent to which an organization evaluates an employee's contribution and is concerned about his or her well-being, with indicators the organization's concern about the employee's well-being, consistency between the organization's goal and value and those of the employee, the organization's concern about the employee, the organization's willingness to assist the employee, the organization's willingness to give forgiveness, and the organization's willingness to prove the employee with opportunities self-efficacy (X3). In this research, self-efficacy is defined as an employee's confidence or belief in his or her ability to organize, perform tasks, achieve goals, produce something, and take action to demonstrate a given skill. There are three main components of self-efficacy measurement scale, namely strength, generality, and level. Work Engagement (Z). In this research, work engagement is defined as a positive attitude arising in an employee toward his or her work, with indicators high mental strength and resilience in work, desire to strive earnestly in work, persistent in facing hardship, enthusiasm in work, work's ability to inspire, work's ability to invoke pride, meaningfulness in the work, challenges posed by the work, the state of being engrossed in work, focus in work, the sense that time passes by in a blink of eye during work, and heavy feeling to release his or herself from work which leads him or her to be unaware of his or her surrounding. Job Satisfaction (Y). In this research, job satisfaction is defined as a good emotional state caused by an employee's judgment on his or her work or experience of a work, with indicators decent amount of salary, salary amount that satisfies expectation and wish, ability of salary to meet needs, fair promotion policy, decision on promotion based on expertise and capacity, promotion regularly applied by the organization, challenges posed by work, interesting and fun work, and the necessity to use critical skills in work.

\section{Research Population and Sample}

The population of this research consisted of employees at above grade 5, numbering 163 employees.

\section{Types of Data Needed}

The data needed to be primary and secondary data. The instrument used in this research was questionnaires. The answers provided for every question were designed in the Likert Scale to test how strongly respondents agreed with the statements, and this scale consisted the following four points, namely 1 = strongly disagree, $2=$ disagree, $3=$ agree, and $4=$ strongly agree.

\section{Results of Research Instrument Testing}

The instrument used in this research was questionnaires. The validity and reliability of the instrument used were tested. The questionnaires consisted of 25 items of variable job 
characteristics, eight items of variable perceived organizational support, 11 items of variable self-efficacy, 20 items of variable work engagement, and 14 items of variable job satisfaction. The results of the validity test showed that all question items had Corrected Item-Total Correlation ( $\mathrm{r}$ count) values greater than $\mathrm{r}$ table value (0.165). Therefore, all question items included in the questionnaires were declared valid. The results of the reliability test showed that the Cronbach Alpha values resulted was greater than 0.6, with job characteristics had a value of 0.895 , perceived organizational support 0.835 , self-efficacy 0.918 , work engagement 0.909 , and job satisfaction 0.916 . In other words, all variables in this research were declared reliable.

\section{Results of Classical Assumption Test}

The results of Multicollinearity test showed a Variance Inflation Factor (VIF) value of below 10 and a tolerance value of greater than 0.10. In other words, the regression model used in this research did not contain any multicollinearity signs. The results of the Heteroscedecity test showed that the significance value was beyond 0.05 ; thus the points were spread randomly in no particular pattern. This means that the regression model proposed in this research did not show any heteroscedasticity sign.

\section{Analysis Methods}

The data in this research were processed using descriptive and inferential statistics, and the research models were simple and multiple linear regression. The hypothesis testing used F test, ttest, and Sobel test.

\section{Results and Discussions}

In this research, questionnaires were distributed to all employees with a grade greater than five at P4TK, numbering 163. The number of questionnaires returned was 101 (61.91\%), all of which could be used as a data source and could be processed in this research. The characteristics of the research respondents showed that the respondents were dominated by males (51 males or 50.5\% of all respondents), respondents aged 46 (55 people of $54.5 \%$ of all respondents), respondents with Bachelor's degree (53 people or $52.57 \%$ of all respondents, and respondents who had worked for more than 26 years (38 people or $37.62 \%$ of all respondents)

\section{Description of Research Variables}

Table 1. Descriptive Analysis of Research Variables

\begin{tabular}{|l|c|c|c|}
\hline \multicolumn{1}{|c|}{ Questions } & Mean & $\mathbf{( \% )}$ & Description \\
\hline Job Characteristics (X1) & 2.98 & 74.5 & High \\
\hline Perceived Organizational Support (X2) & 2.83 & 70.7 & High \\
\hline Self-Efficacy (X3) & 3.12 & 80.4 & High \\
\hline Work Engagement (Z) & 3.02 & 75.5 & High \\
\hline Job Satisfaction (Y) & 2.94 & 73.5 & High \\
\hline
\end{tabular}

Sources: Processed Primary Data, 2016

Table 1 showed that the variable job characteristics had a mean value of 2.98 (high). According to Saks (2006), work design with job characteristics model will invoke the sense of work meaningfulness, which will trigger the sense of engagement in employees with their job. The 
variable perceived organizational support had a mean value of 2.83 (high). Rich (2010) argued that perceived organizational support would have a positive, significant effect on work engagement, and the employees will feel more engaged with their job if they perceived the organizational support as high. The variable self-efficacy had a mean value of 3.12 (high). Robbins \& Judge (2017) argued that the higher the levels of self-efficacy of an individual, the higher the levels of his or her confidence in his or her ability to achieve success. Therefore, with higher levels of self-efficacy, employees are expected to be more confident in executing and completing their tasks, be more active, and be able to handle challenges or hardship in their job. The variable work engagement had a mean value of 3.02 (high). The results of the research by Mache et al. (2014) proved that work engagement had a positive, significant effect on job satisfaction, both satisfaction with life and satisfaction with the job. The variable job satisfaction had a mean value of 2.94 (high). Kreitner \& Kinicki (2013) stated that when an employee feels dissatisfied with his or her job, there is a high likelihood that he or she will show negative attitudes toward his or her job, for example, increased absenteeism, increased turnover, he or she becomes stressed, and decreased performance. In another perspective, there are some positive consequences resulted from job satisfaction. These positive consequences are in the form of positive attitudes that go hand in hand with the employees' satisfaction, for example, improved motivation, improved work engagement, increased organizational commitment, better organizational citizenship behaviour, and increased performance.

\section{Table 2. Hypothesis Results}

\begin{tabular}{|c|l|c|}
\hline No & \multicolumn{1}{|c|}{ Hypothesis } & Description \\
\hline H1a & Job characteristics influence work engagement. & Supported \\
\hline H1b & Perceived organizational support influence work engagement. & Supported \\
\hline H1c & Self-efficacy influence work engagement. & Supported \\
\hline H1d & $\begin{array}{l}\text { Job characteristics, perceived organizational support, and self-efficacy } \\
\text { influence work engagement. }\end{array}$ & Supported \\
\hline H2a & Job characteristics influence job satisfaction. & Supported \\
\hline H2b & Self-efficacy influence job satisfaction. & Supported \\
\hline H2c & Organizational characteristics influence organizational commitment. & Supported \\
\hline H2d & $\begin{array}{l}\text { Job characteristics, perceived organizational support, and self-efficacy } \\
\text { influence job satisfaction. }\end{array}$ & Unsupported \\
\hline H3 & Work engagement influences job satisfaction. & $\begin{array}{l}\text { The direct influence (job characteristic, perceived organizational support } \\
\text { and self-efficacy on job satisfaction) is greater than the indirect influence } \\
\text { (job characteristic, perceived organizational support and self-efficacy on job } \\
\text { satisfaction through work engagement) }\end{array}$ \\
\hline
\end{tabular}

Sources: Processed Primary Data, 2016

\section{Influence of Job Characteristics on Work Engagement}

The results of this study showed that there is a significant positive influence of job characteristics on job engagement. The results of this study are in line with Saks' study (2006) indicated that job characteristics become strong predictors of the emergence of work engagement. Employees with high job characteristics will feel more attached to their work. The results of this study also supported the results of research by Kittredge (2010), which also stated that job characteristics have a significant relationship to work engagement. 
When the employee of P4TK Arts and Culture Yogyakarta feels that his job is a meaningful job, knowing how far he becomes the key to the quality of the unit work, and knowing the extent of his good or bad work, then the employee sense of work engagement will occur. When employees are engaged in every work activity, being assigned to jobs that require unique competencies, being given the opportunity to participate in decisions, this will create the sense of employee's engagement to work. This is supported by the research results of Akingbola \& Van Den Berg (2017) which concluded that employee job satisfaction is significantly due to their meaningful work for the public interest and the appropriateness of the employee value with the value carried by the organization.

\section{Influence of Perceived Organizational Support on Work Engagement}

The results of this study indicated that there is a positive influence that is not significant perceived organizational support to work engagement. The results of this study strengthened the research by Nusantria, (2011) which stated that the perceived organizational support is positive but not significant to the work engagement, there is a positive influence of perceived organizational support variable to work engagement. The results also strengthened research by Saragih et al., 2013 which stated in hierarchy regression analysis results that the perceived organizational support is positively related but not significant to the work engagement both engagement to organization and engagement to his work.

However, the results of this study are not in line with Rich's research (2010), which stated that the perceived organizational support has a positive and significant effect on the emergence of work attachment, the employee will feel more attached to his work if the perception felt by the individual is high. This study also does not support the results of Burns (2016) research which stated that the perceived organizational support has a positive and significant effect on the attachment of work, the perceived organizational support becomes the independent variable and the predictor of the emergence of work engagement. Likewise, it is not in line with Jin \& McDonald's (2016) research which proves that specifically it is found that there is a positive relationship between the perceived organizational support and work engagement. The differences in the results of this study with these studies occurred at the level of significance of the influence of perceived organizational support variable to work engagement. This may be due to the differences between this study and previous studies. First, the difference in the number of respondents used. Second, the theory used, and third, its analysis tool. To reveal the cause of the insignificant results on the relationship between perceived organizational support to employee attachment to the employee, we added qualitative data obtained from interviews with the Head of Sub-division and Personnel of P4TK of Arts and Culture of Yogyakarta, Mr Machludin Budiyanto. From the interview result, it can be concluded that the individual in P4TK already loves his work especially individuals who deepen the art and culture both from educational backgrounds and individuals who are involved in the arts such as music, craft, batik, and others. P4TK employees with art and cultural backgrounds are different from individuals working in other organizations precisely in the administrative section where every day it is related to paper and writing.

From the above statement, it is mentioned that art people work because they are having fun and have a deep interest in work. Even if they work without being paid, they will still feel happy and serious in completing the work. P4TK employees already know that the salary is a reward that 
the organization will give them if they can complete the targets of the Employee Performance Goals of each individual so that the main thing is how they work well and love their work, not from the rewards given after they finish their work. It is suspected to be the cause there is no significant effect between the perceived organizational support the work engagement.

According to Eisenberger et al. (1986), employees who feel high organizational support tend to give positive attitudes to their work, with a certain amount of material or social rewards, employees respond with more contributions to the organization.

\section{Influence of Self-Efficacy on Work Engagement}

The results of this study indicated that there is a significant positive influence of self-efficacy on work engagement. The results of this study are in line with the Yakin \& Erdil's research (2012) that found that self-efficacy significantly affects work engagement, confidence has a positive and significant relation to the overall dimension of work engagement. This study also supported the study of Schaufeli \& Salanova (2007) which stated that self-efficacy has a positive and significant effect of the emergence of work engagement, self-efficacy is a very suitable predictor to generate work engagement. This research also supported the research of Sukmawati et al. (2015) which stated that personal resources consisting of self-efficacy have a direct influence on work engagement (Sukmawati et al., 2015: 18). Research Mache et al., (2014) also stated that self-efficacy has a significant relationship to engagement.

Employees with high self-efficacy will be more confident in doing and completing the task, more active, and able to handle challenges or difficulties in the work. According to Mache et al. (2014), high self-efficacious self-employment survives even in completing tasks the challenges keep coming. Robbins \& Judge (2017) argued that the higher the level of individual self-efficacy the higher a person's confidence level on his ability to achieve success.

\section{Influence of Job Characteristics Perceived Organizational Support, and Self-Efficacy on Work Engagement Influence of Self-Efficacy on Work Engagement}

The results of this study indicated that work characteristics, perceived organizational support, and self-efficacy have a significant positive influence on work engagement. The results of this study are in line with Kittredge (2010) research which stated that job characteristics, perceived organizational support and self-efficacy have a positive relationship to work engagement. The results of this study also support the research Saks (2006) which stated that the characteristics of work and the perceived organizational support is the antecedent emergence of work engagement, Job Characteristics and perceived organizational support has a simultaneous effect on the emergence of work engagement.

The results of this study revealed that when there is a psychological condition of meaningfulness of work (resulting from work characteristics), psychological conditions of safety (resulting from the perceived organizational support), and psychological conditions availability (resulting from self-efficacy) then an employee P4TK Art and Culture Yogyakarta will bring a sense tied to the work which will create a positive employee attitude to work or organization. This is in line with Kahn (1990) who explained that someone would be bound to his work if there are psychological conditions of meaning, psychological conditions of security, and psychological conditions availability. P4TK employees Art and Culture Yogyakarta feel attached to their work when their 
work is designed with job model work characteristic design, the availability of support from the organization, and individual beliefs about ability and competence.

\section{Influence of Job Characteristics on Job Satisfaction}

The results showed that there is a significant positive effect of job characteristics on job satisfaction. The results of this study are in line with the research of Ali et al. (2014) which stated that there is a positive and significant relationship between the five dimensions of job characteristics to job satisfaction. The results of this study also support the research of Milette \& Gagne (2008), which proved that job characteristics give positive and significant influence to the positive attitudes of employees to their work, one of them is job satisfaction. The results also support Hung \& Huang (2014) research which proved that job characteristics consisting of variety, autonomy, identity, feedback, cooperation, and friendship have a positive and significant impact on job satisfaction. The results of this study also supported the research of Hauff et al., (2015) who found that the important factors to drive job satisfaction consisted of interesting work, good relationships between employees and managers and colleagues in the workplace. Employed workers challenge, jobs identified from start to finish, jobs with major internal or external environmental impacts, are autonomous in completing work, and given clear information about the work or performance will elicit a positive perception of the organization, so that they driven and motivated to work harder, when they are satisfied with their work then in doing the next job they will give better performance.

\section{Influence of Perceived Organizational Support on Job Satisfaction}

The result of this study showed that there is a significant positive impact on perceived organizational support toward job satisfaction. Research of Hasan et al. supported this result of this study., (2014) stating that perceived organizational support has a positive and significant effect on job satisfaction. Furthermore, this research also supports the research of Shacklock et al., (2013) who proved that there is a significant relationship between the perceived organizational support toward satisfaction. This research is also in line with the research of Biswas \& Bhatnagar (2013) saying that perceived organizational support has a positive relationship toward job satisfaction.

Nevertheless, Rhoades et al., (2001) suggested that an employee who has high perceived organizational support feels that whenever they need support related to the job or other things associated to their life, the organization is always willing to help, besides, the perceived organizational support also gives certainty to the employees whom organization will help to do their job effectively and efficiently. Chiang \& Hsieh in Hasan et al., (2014) argued that whenever the organization gives support to the employees, they will feel appreciated and respected, nevertheless when the employees feel that the organization supports them, the employees will improve their working performance and become more persistent. Based on this mutual principle, the employees who have perceived organizational support will not only help the subordinates and colleagues but also improve their performance and their satisfaction. The perceived organizational support felt by the employees of P4TK Art, and Culture Yogyakarta emerges a positive attitude between them and their job, so an intrinsic motivation will come out which later will initiate the employees always to work better. The employees will feel satisfied when the organization always encourages and assists them in the scope of the work. 


\section{Influence of Self-Efficacy on Job Satisfaction}

This research showed that there is a significant positive influence of self-efficacy toward job satisfaction. This research strengthens the research of Kuru \& Katsaras (2016) stating that there is no significant correlation between job satisfaction and the self-efficacy. This research is also congruent with the research of Duggleby et al. (2009) arguing that the self-efficacy does not have a significant effect on job satisfaction. Moreover, Kuru \& Katsaras (2016) proposed that there is no significant effect on self-efficacy and job satisfaction. In this research, however, it was proven that there is no correlation between the job satisfaction and self-efficacy variable owned by the nurses in Greece. Furthermore, the research of Kuru \& Katsaras (2016) added that an individual would feel satisfied with his/her job due to some work elements such as the satisfaction of the salary as the expectation, and the location was chosen where the nurses work (service point) as the expectation of those nurses. Also, Kuru \& Katsaras, (2016) also added that the small total of the sample mainly caused the result.

However, this research is different from the research of Borgogni et al., (2013) who stated that the self-efficacy has a positive and significant effect on job satisfaction. An individual who is confident of his/her competence and believes that he/she can control his/her job will fell more satisfied with his/her job. This result of this study is also different from the research of Lai \& Chen (2012) who concluded that that self-efficacy has a positive relationship toward job satisfaction. Moreover, an individual with high self-efficacy will have superior experience and skill where those factors can elevate the job satisfaction and employee's performance.

The amount of the research respondents probably causes the differences of this research with the previous researches. Besides, according to FIlho et al., (2001), if the total of research respondents and the complexity are getting higher, then the estimation of the statistic will be consistent. In addition, the determination of the random sample with the big sample total will decrease the data variability level so the research will be more bias and efficient. By increasing the sample size, the effect discovered statistically will be significant in the huge sample size where most of the effects will be significant.

In order to disclose the result of insignificant result of the relation between the self-efficacy toward job satisfaction of the employees, we added qualitative data obtained through interview result of the Head of the Department of Administration and Employment of P4TK institution of Art and Culture Yogyakarta, namely Mr Machludin Budiyanto. From the interview result, it is concluded that the job satisfaction of the employees of P4TK Art and Culture Yogyakarta is achieved when the internal target of the employees was accomplished well, the practical result done by the employees can be used by the customer, and the institution can fulfil its function and the task. Besides, the employee will feel satisfied with their job when the organization, one of them reward them is remuneration.

\section{Influence of Job Characteristics Perceived Organizational Support, and Self-Efficacy on Job Satisfaction}

The result of this research showed that collectively, the variable of job characteristics, perceived organizational support, and self-efficacy have a positive and significant influence on job satisfaction. This result of this research supports the research of Saks (2006) stating that job characteristics consisted of five job dimensions and the organization's support have a 
simultaneous effect on the occurrence of job satisfaction. The organization factors and selfpersonal factors have collective impacts on job satisfaction. Likewise, when the organization designs a job with the job characteristics model, the organization concerns the employee's welfare accompanied with high self-confidence owned by the employees, then they will feel satisfied with their job. Moreover, when an individual is given more responsibility for the completion of their duty and job, an individual will feel more satisfied with their job. The organization's support affects the positive attitudes emerged by the employees toward their job, one of them is job satisfaction. Lai \& Chen (2012) also explained that the higher the confidence of the employees of their competence and skill in completing their job, and the confidence that they can face any challenge, barrier, and obstruction that appear when they perform their job is, the higher the job satisfaction felt by the employees.

\section{Influence of Work Engagement on Job Satisfaction}

The research of this result identified that there is a positive and significant influence between work engagement and job satisfaction. This result is in line with the research of Ramos \& Almeida (2017) explaining that work engagement has a positive and significant effect on job satisfaction. It is furthermore supported by the research of Mache et al. (2012) proving that work engagement has a positive and significant effect toward the satisfaction of employees either life satisfaction or job satisfaction. The higher the work engagement possessed by the employee is, the higher the outcome of the job. The work engagement can increase the employees' concentration when they complete their duty, perform their job, and grow a commitment toward the institution. The impact of employees' work engagement furthermore is closely related to the organizational variable such as job satisfaction. The more the employees are engaged in their job, the more satisfied the employee is. It is congruent with the opinion of Saks (2006) stating that employee's work engagement (engagement toward work and organization) has a positive and significant relationship toward the occurrence of job satisfaction. Also, to that, an employee who has a deep concentration toward the job has dedication and spirit that makes them persistent in overcoming a problem and considers that their job is a meaningful job and always keeps the focus and concentration in accomplishing their job.

\section{Path Analysis}

Based on the result of the path analysis result, the data showed that the result of this path analysis in this research showed that there is a direct bigger effect between the job characteristics and perceived organizational support toward the job satisfaction rather than the indirect effect through work engagement. Moreover, there is an indirect bigger effect between self-efficacy and job satisfaction through work engagement.

Thus, this research supports the research of Saks (2006) proposing that the direct effect of job satisfaction and perceived organizational support toward job satisfaction is bigger than the indirect effect of job characteristics and organization's support perception toward job satisfaction through job engagement. The result of this research also supports the research of Yakin \& Erdil (2012) saying that there is a work engagement mediation effect between the efficacy relation and job satisfaction. 


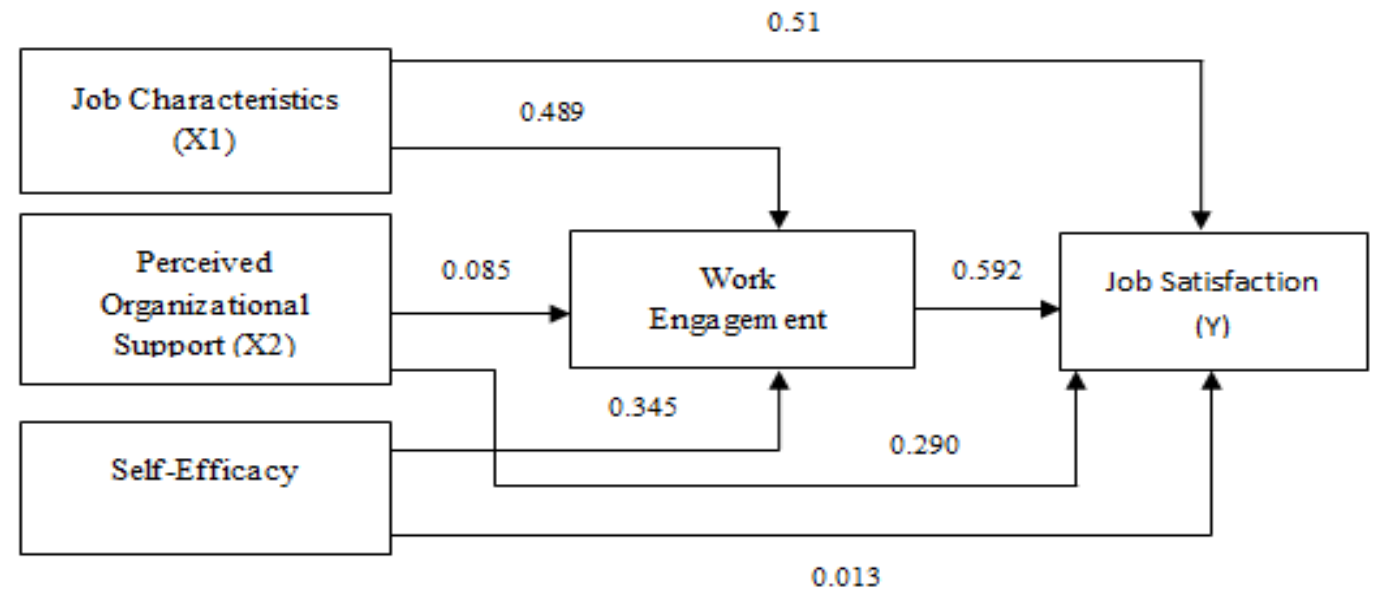

Source: Output, primary data processed

Figure 1. Result of Path Analysis

\section{Conclusion and Suggestion}

The result of this research concluded that first, job characteristics and self-efficacy partially have positive and significant effects on work engagement. Meanwhile, the organization's support perception partially has an insignificant yet positive effect on work engagement. Collectively, the job characteristics, the perceived organizational support, and the self-efficacy have a positive and significant effect toward the work engagement. Second, the job characteristics and perceived organizational support have a positive yet insignificant effect on job satisfaction. On the other hand, self-efficacy has a positive yet insignificant effect on job satisfaction. Collectively, the job characteristics, the perceived organizational support, and the self-efficacy simultaneously have a positive and significant effect on job satisfaction. Third, work engagement has a positive and significant effect on job satisfaction. Fourth, the job characteristics and the perceived organizational support affects directly, while the self-efficacy indirectly affects the job satisfaction through work engagement.

For employees, based on the result of this research, it is suggested that: first, it is expected that staff can maintain their self-confidence of competence and skill. Second, staff should be able to create and maintain a supportive working environment. Third, staff should be able to build teamwork and support each other orally toward the colleagues either in trouble or not.

For managers of the organization, it is suggested that: first, creating a comfortable and supportive working environment for the job performed by staff is crucial. Secondly, leaders must act as a good model and have time to assist staff when they have problems to complete their duties. Third, staff should be empowered to complete their job in the best possible manner. Fourth, a fair promotion policy should exist based on the skills needed in filling the position.

Future researchers are expected to: first, additional factors that affect the work engagement which cannot be found in this research, namely emotional intelligence, leadership and work condition variable. Second, additional factors that affect job satisfaction which cannot be found in this research, such as the variable of the working environment, employees' teamwork, status, and organization culture. Third, add the respondent amount. 
IJBE (Integrated Journal of Business and Economics)

e-ISSN: 2549-3280/p-ISSN: 2549-5933

\section{Acknowledgement}

Thanks to Allah SWT for his mercy and guidance in giving me the full strength to complete this paper. I offer my sincere appreciation for the learning opportunities provided my institution (Islamic University of Indonesia). A lot of thanks to the Centre for the Development and Empowerment of Educators and Educational Personnel (P4TK) of Art and Culture of Yogyakarta and their employees, for giving me permission and great cooperation. Besides, grateful acknowledgement to all of my friends who never give up in giving their support to me in all aspects of life. Thank you very much, my friends, I will never forget all of your kindness.

\section{References}

1) Akingbola, K. \& Van Den Berg, A. H. (2017). Antecedents, Consequences, and Context of Employee Engagement in Nonprofit Organizations, Review of Public Personnel Administration, 1-29.

2) Ali, M. A. S. et al. (2014), Hackman and Oldham's Job Characteristics Model to Job Satisfaction, Social and Behavioral Sciences, 129: 46-52.

3) Bandura, A. (1997). Self-Efficacy the Exercise of Control, United States of America: W.H Freeman and Company.

4) Bedakar, M. \& Pandita, D. (2014), A study on the drive of employee engagement in impacting employee performance, Social and Behavioral Sciences, 133: 106-115

5) Biswas, S. \& Bhatnagar, J. (2013), Mediator Analysis of Employee Engagement: Role of Perceived Organizational Support, P-O Fit, Organizational Commitment, and Job Satisfaction, The Journal For Decision Makers, 38 (1): 27-40.

6) Bohlander, G., Snell, S. (2013), Managing Human Resources, South-Western: Cengage Learning.

7) Borgogni, L. et al. (2013), The role of self-efficacy and job satisfaction on absences from work, Revue européenne dePsychologiee appliquée 63 (3): 129-136.

8) Burns, L. K. (2016), Perceived Organizational Support and Perceived Supervisor Support as Antecedents of Work Engagement. Master's Theses. SanJose State University.

9) Colquitt, A. J, Lepine, A. J.; Wesson, J. M.(2013), Organizational BehaviorImproving Performance and Commitment in the Workplace, Edisi ketiga, New York: McGraw-Hill Companies, Inc.

10) Duglebby, W., Cooper, D.; Penz, K.(2009), HopeSelf-efficacy, Spiritual Well-being, g and Job Satisfaction, Journal of Advanced Nursing, 65 (11): 2376-2385.

11) Eisenberger, R.et al. (1986), Perceived Organizational Support, Journal of Applied Psychology, 71 (3): 500-507.

12) Eisenberger, R.et al. (1997), Perceived Organizational Support, Discretionary Treatment, and Job Satisfaction, Journal applied Psychology, 82 (5): 812-820.

13)___et al. (2001), Reciprocation of Perceived Organizational Support, Journal of Applied Psychology, 86 (1): 825-836.

14) Filho, F. B. D.et al., (2013), When is statistical significance not significant?, Brazilian Political Science Review, 7 (1): 31-55.

15) Hassan, S., Hassan, M.; Shoaib, M.(2014), Measuring the Impact of Perceived Organizational Support, Psychological Empowerment, $\mathrm{t}$ and Rewards on Employee's Satisfaction: Testing the Mediating Impact of Employee Engagement, World Applied Sciences Journal, 30 (5): 625-660.

16) Hauff, S., Ritcher, F. N.; Tressin, T. (2015), Situational job characteristics and job satisfaction: The moderating role of national culture, International Business Review. 24 (4): 710-723.

17) Hung, L. \& Huang, C. M. (2014), An analysis of the relations among job characteristics, manager leadership behaviors and employee's job satisfaction- The case of Taiwanese tax officials, African Journal of Business Management. 8 (15): 612-625. 
IJBE (Integrated Journal of Business and Economics)

e-ISSN: 2549-3280/p-ISSN: 2549-5933

18) Jin, H. M. \& McDonald, B. (2016), Understanding Employee Engagement in the Public Sector: The Role of Immediate Supervisor, Perceived Organizational Support, and Learning Opportunities, American Review of Public Administration, 1-23.

19) Kahn, A. W. (1990), Psychological Conditions of Personal Engagement And Disengagement at Work, Academy of Management Journal, 33 (4): 692-724.

20) Kittredge, A. (2010), Predicting Work and Organizational Engagement with Work and Personal Factors, Master's Theses, SanJose State University.

21) Kreitner, R. \& Kinicki, A. (2013), Organizational Behaviour, Edisi kesepuluh, New York: McGrawHill Companies, Inc.

22) Krishnan, R.et al. (2015), Employee Work Engagement: Understanding the Role of Job Characteristics and Employee Characteristics, Journal of Applied Environmental and Biological Sciences, 4 (10): 58-67.

23) Kuru, N. \& Katsaras, T. (2016), Job satisfaction and Perceived Self-Efficacy among Greek Nurses, International Journal of Humanities and Social Science Invention. 5 (9): 08-14.

24) Lai, C. M. \& Chen, C. Y. (2012), Self-Efficacy, Effort, Job Performance, Job Satisfaction, and TurnoveIntentionson: The Effect of Personal Characteristics on Organizational Performance, International Journal of Innovation, Management and Technology.3 (4): 387-391.

25) Mache, S.et al. (2014), Exploring the impact of resilience, self-efficacy, optimism and organizational resources on work engagement, IOS press. 47 (4): 491-500.

26) __ (2014), Surgeons' work engagement: Influencing factors and relations the o job and life satisfaction, The surgeon, journal of the Royal Colleges of Surgeons of Edinburgh and Ireland, 12 (4): 181-190.

27) Millette, V. \& Gagne, M. (2008). Designing volunteers' tasks to maximize motivation, satisfaction, $n$ and performance: The impact of job characteristics on volunteer engagement, Motivation, $n$ and Emotion. 32 (1): 11-22.

28) Nusantria, S. (2012), Employee Engagement: Anteseden dan Konsekuensi, Skripsi Sarjana, Semarang: Fakultas Ekonomi dan Bisnis Universitas Diponegoro.

29) Ramos, O. A. \& Almeida, D. H. (2017), Work engagement, social support, and job satisfaction in Portuguese nursing staff: A winning combination, Applied Nursing Research. 36: 37-41.

30) Rhoades, L. \& Eisenberger, R. (2002), Perceived Organizational Support: A review of the Literature, Journal of Applied Psychology, 87 (4): 698-714.

31) Rich, L. B., Lepine, A. J.; Crawford, R. E. (2010), Job Engagement: Antecedents and Effects on Job Performance, Academy of Management Journal, 53 (3): 617-635.

32) Robbinson, P. S. \& Judge, T. A.(2017), Organizational Behavior, Edisi 17, England: Pearson Education Limited.

33) Saks, M. A. (2006), Antecedents inconsequences of Employee Engagement. Journal of Managerial Psychology, 21 (7): 600-619.

34) Schaufeli, B. W.et al. (2002), Two-Sample Confirmatory Factor Analytic Approach, Journal of Happiness Studies, 3: 71-92

35) Schaufeli, B. W.\& Salanova, M. (2007), Efficacy or inefficacy that is the question: Burnout and work engagement, and their relationships with efficacy beliefs, Anxiety, Stress, and Coping. 20 (2): 177196.

36) Shacklock, K.et al. (2013), The role of support antecedents in nurses' intentions to quit: the case of Australia, Journal of Advanced Nursing, 70 (4): 811-822.

37) Sukmawati, A. et al. (2015), Pengaruh Job Demands, Job Resources dan Personal Resources terhadap Work Engagement, Jurnal Aplikasi Bisnis dan Manajemen (JABM), 1 (1):12-22.

38) Yakin, M. \& Erdil, O. (2012), Relationships Between Self-Efficacy and Work Engagement and the Effects on Job Satisfaction: A Survey on Certified Public Accountants, Social and Behavioral Sciences, 58: 370-378. 